\title{
Transcutaneous carbon dioxide application suppresses bone destruction caused by breast cancer metastasis
}

\author{
TOSHIYUKI TAKEMORI ${ }^{1}$, TERUYA KAWAMOTO ${ }^{1,2}$, TAKESHI UEHA $^{3,4}$, MITSUNORI TODA $^{5}$, \\ MASAYUKI MORISHITA ${ }^{1}$, ETSUKO KAMATA ${ }^{1}$, NAOMASA FUKASE ${ }^{1}$, HITOMI HARA ${ }^{1}$, \\ SHUICHI FUJIWARA ${ }^{1}$, TAKAHIRO NIIKURA ${ }^{1}$, RYOSUKE KURODA ${ }^{1}$ and TOSHIHIRO AKISUE ${ }^{1,6}$ \\ ${ }^{1}$ Department of Orthopaedic Surgery, Kobe University Graduate School of Medicine, Chuo-ku, Kobe 650-0017; \\ ${ }^{2}$ Division of Orthopaedic Surgery, Kobe University International Clinical Cancer Research Center, Chuo-ku, \\ Kobe 650-0047; ${ }^{3}$ Division of Rehabilitation Medicine, Kobe University Graduate School of Medicine, Chuo-ku, \\ Kobe 650-0017; ${ }^{4}$ NeoChemir Inc., Chuo-ku, Kobe 651-0087; ${ }^{5}$ Department of Orthopaedic Surgery, \\ Hyogo Rehabilitation Centre, Nishi-ku, Kobe 651-2181; ${ }^{6}$ Department of Rehabilitation Science, \\ Kobe University Graduate School of Health Sciences, Suma-ku, Kobe 654-0142, Japan
}

Received March 25, 2018; Accepted July 4, 2018

DOI: 10.3892/or.2018.6608

\begin{abstract}
Hypoxia plays a significant role in cancer progression, including metastatic bone tumors. We previously reported that transcutaneous carbon dioxide $\left(\mathrm{CO}_{2}\right)$ application could decrease tumor progression through the improvement of intratumor hypoxia. Therefore, we hypothesized that decreased hypoxia using transcutaneous $\mathrm{CO}_{2}$ could suppress progressive bone destruction in cancer metastasis. In the present study, we examined the effects of transcutaneous $\mathrm{CO}_{2}$ application on metastatic bone destruction using an animal model. The human breast cancer cell line MDA-MB-231 was cultured in vitro under three different oxygen conditions, and the effect of altered oxygen conditions on the expression of osteoclast-differentiation and osteolytic factors was assessed. An in vivo bone metastatic model of human breast cancer was created by intramedullary implantation of MDA-MB-231 cells into the tibia of nude mice, and treatment with $100 \% \mathrm{CO}_{2}$ or a control was performed twice weekly for two weeks. Bone volume of the treated tibia was evaluated by micro-computed tomography $(\mu \mathrm{CT})$, and following treatment, histological evaluation was performed by hematoxylin and eosin staining and immunohistochemical staining for hypoxia-inducible factor (HIF)-1 $\alpha$, osteoclast-differentiation and osteolytic factors, and tartrate-resistant acid phosphatase (TRAP) staining for osteoclast activity. In vitro experiments revealed that the mRNA
\end{abstract}

Correspondence to: Dr Teruya Kawamoto, Department of Orthopaedic Surgery, Kobe University Graduate School of Medicine, 7-5-1 Kusunoki-cho, Chuo-ku, Kobe 650-0017, Japan

E-mail: trykwmt@med.kobe-u.ac.jp

Key words: breast cancer, bone metastasis, bone destruction, hypoxia, transcutaneous application, carbon dioxide $\left(\mathrm{CO}_{2}\right)$, osteoclast expression of RANKL, PTHrP and IL-8 was significantly increased under hypoxic conditions and was subsequently reduced by reoxygenation. In vivo results by $\mu \mathrm{CT}$ revealed that bone destruction was suppressed by transcutaneous $\mathrm{CO}_{2}$, and that the expression of osteoclast-differentiation and osteolytic factors, as well as HIF-1 $\alpha$, was decreased in $\mathrm{CO}_{2}$-treated tumor tissues. In addition, multinucleated TRAP-positive osteoclasts were significantly decreased in $\mathrm{CO}_{2}$-treated tumor tissues. Hypoxic conditions promoted bone destruction in breast cancer metastasis, and reversal of hypoxia by transcutaneous $\mathrm{CO}_{2}$ application significantly inhibited metastatic bone destruction along with decreased osteoclast activity. The findings in this study strongly indicated that transcutaneous $\mathrm{CO}_{2}$ application could be a novel therapeutic strategy for treating metastatic bone destruction.

\section{Introduction}

Breast cancer is the primary cause of cancer mortality in women (1), with bones among the most common metastatic sites $(2,3)$. Bone metastasis increases skeletal-related events (SREs), which are defined as pathological fractures, spinal cord compression and bone pain requiring palliative radiotherapy and/or surgical treatment, and worsens the activities of daily living and patient quality of life. Bone destruction associated with cancer metastasis is caused by activated osteoclast function, but not by the direct effects of cancer cells in the bone (4). For osteoclast activity, receptor activator of nuclear factor $\kappa-B$ ligand (RANKL) promotes osteoclast differentiation, formation and bone-resorptive ability by binding to its receptor, RANK, which is expressed in both hematopoietic osteoclast-precursor cells and mature osteoclasts. In the area of bone metastasis, cancer cells produce several osteolytic factors, including parathyroid-hormone-related peptide (PTHrP), interleukin (IL)-1 $\beta$, IL-6 and IL-8, each of which can stimulate osteoblasts and/or stromal cells to increase RANKL expression (5-7). Additionally, RANKL is also expressed in 
metastatic cancer cells $(8,9)$, with its overexpression in the area of bone metastasis inducing osteoclast activation (10). Recently, osteoclast function was focused on as a therapeutic target in metastatic bone tumors, and several inhibitors of osteoclast activity, such as bisphosphonates and denosumab, have been developed and used to prevent metastatic bone destruction. However, the effects of these treatment modalities remain limited. In addition, osteonecrosis of the jaw and hypocalcemia represent serious side-effects and long-term prognosis associated with these treatments remains unknown (11-14).

Hypoxia is a common feature of malignant tumors, including metastatic bone tumors. Tumor hypoxia is caused by an inadequate supply of oxygen that occurs when the tumor outgrows its blood supply, resulting in chronic hypoxia and the inability of oxygen to reach some cells due to the large diffusion distance (15-17). Hypoxia strongly contributes to the reduced efficacy of certain chemotherapeutic agents and/or radiotherapy and represents a major cause of tumor propagation $(15,16,18)$. Additionally, tumor-associated hypoxia plays a significant role in tumor progression associated with bone metastasis $(19,20)$. Hypoxic conditions allow factors, such as hypoxia-inducible factor-1 (HIF-1), to overexpress and trigger the production of angiogenic proteins $(17,21,22)$. HIFs are essential factors for maintaining cellular oxygen homeostasis and adaptation to hypoxic environments. HIF-1 $\alpha$, an oxygendependent $\alpha$ subunit of HIF (23), is activated by hypoxia and induces RANKL expression. Increased hypoxia accompanied by HIF-1 overexpression also promotes the progression of bone metastasis in breast cancer $(24,25)$. Therefore, tumor hypoxia can be considered as an attractive therapeutic target involved with bone metastases.

To obtain local oxygenation in tumor tissues, a direct absorption of oxygen through the skin can be considered, however oxygen is not easily absorbed through the skin (26). We previously demonstrated that transcutaneous $\mathrm{CO}_{2}$ application could lead to increased oxygen release from red blood cells, known as a physiological phenomenon, the Bohr effect $(27,28)$. Oxygenation in treated tissues could be easily and effectively induced by the transcutaneous $\mathrm{CO}_{2}$ treatment via the oxygen dissociation from hemoglobins (28). Using the $\mathrm{CO}_{2}$ treatment, we could induce mitochondrial apoptosis in human cancer xenografts and improve hypoxia in cancer tissues in the absence of side-effects (29-32). Based on these findings, we hypothesized that hypoxia would promote bone destruction via the activation of factors related to osteoclast differentiation and osteolysis, and that recovery from hypoxia following transcutaneous $\mathrm{CO}_{2}$ application would inhibit bone destruction by cancer metastasis. In the present study, we examined whether oxygen conditions affect the expression of osteoclast-differentiation and osteolytic factors in vitro, as well as the effects of recovery from hypoxia following transcutaneous $\mathrm{CO}_{2}$ application on bone destruction and osteoclast activity using an in vivo bone metastatic model of breast cancer.

\section{Materials and methods}

Cell lines. The human breast cancer cell line MDA-MB-231 was obtained from the American Type Culture Collection (ATCC; Manassas, VA, USA) (33), and cells were grown as monolayers in Dulbecco's modified Eagle's medium
(DMEM; Sigma-Aldrich; Merck KGaA, St. Louis, MO, USA) supplemented with $10 \%$ (v/v) fetal bovine serum (FBS; SigmaAldrich; Merck KGaA), $100 \mathrm{U} / \mathrm{ml}$ penicillin and $100 \mu \mathrm{g} / \mathrm{ml}$ streptomycin. The cultures were maintained in a humidified atmosphere with $5 \% \mathrm{CO}_{2}$ at $37^{\circ} \mathrm{C}$.

In vitro experiments. To investigate the effect of altered oxygen conditions on breast cancer cells in vitro, MDA-MB-231 cells were incubated for 6 days in one of three different oxygen conditions: normoxic $\left(20 \% \mathrm{O}_{2}, 5 \% \mathrm{CO}_{2}\right)$, hypoxic $\left(2 \% \mathrm{O}_{2}, 5 \%\right.$ $\mathrm{CO}_{2}$ ) or reoxygenated conditions. For the reoxygenated condition, cells were incubated under normoxic conditions $\left(20 \% \mathrm{O}_{2}\right.$, $5 \% \mathrm{CO}_{2}$ ) for 3 days followed by 3 days of incubation under hypoxic conditions $\left(2 \% \mathrm{O}_{2}, 5 \% \mathrm{CO}_{2}\right)$, as previously described (30,32). Following incubation, total RNA was collected from the cells and the mRNA levels of RANKL, PTHrP, $I L-1 \beta, I L-6$ and $I L-8$ were evaluated by quantitative real-time polymerase chain reaction (qPCR).

Animal models. Female BALB/c nude mice aged 5 weeks old were obtained from CLEA Japan Inc. (Tokyo, Japan). Animals were maintained under pathogen-free conditions in accordance with institutional guidelines. Animals were fed pathogen-free laboratory chow and allowed free access to autoclaved water in an air-conditioned room with a 12-h light/dark cycle. All animal experiments were approved by the Ethics Committee of the Kobe University Animal Experimentation Regulations (permission no. P120404-R1). To create the in vivo bone metastasis model of breast cancer, 18 mice were randomly divided into two groups: a $\mathrm{CO}_{2}$-treated group $\left(\mathrm{CO}_{2}\right.$ group; $\left.\mathrm{n}=9\right)$ and a control group $(n=9)$. MDA-MB-231 cells $\left[1.0 \times 10^{6}\right.$ cells in $10 \mu l$ phosphate-buffered saline (PBS)] were intramedullary implanted into the proximal epiphysis of the tibia of all mice in both groups (34). For surgical procedures, mice were anesthetized by intraperitoneal injection of $20-30 \mathrm{mg} / \mathrm{kg}$ pentobarbital sodium for induction and isoflurane inhalation at a concentration of $2 \%$ for maintenance.

Transcutaneous $\mathrm{CO}_{2}$ application . Transcutaneous $\mathrm{CO}_{2}$ application was performed as previously described (30-32,35). Briefly, the area of skin around the lower limb where MDA-MB-231 cells were implanted was treated with $\mathrm{CO}_{2}$ hydrogel. This area was then sealed with a polyethylene bag, and $100 \% \mathrm{CO}_{2}$ gas was administered into the bag. Mice in the control group were treated similarly, replacing $\mathrm{CO}_{2}$ with room air.

In vivo studies. Examination of the in vivo effects of transcutaneous $\mathrm{CO}_{2}$ application on breast cancer bone metastasis was performed following treatment $\left(\mathrm{CO}_{2}\right.$ or air) at 4-week post-implantation of MDA-MB-231 cells and for $10 \mathrm{~min} /$ mouse, twice weekly for 2 weeks. The tumor volume and body weight were monitored twice weekly until the end of the treatment. Tumor volume was calculated as previously described according to the formula $\mathrm{V}=\pi / 6 \times \mathrm{a}^{2} \mathrm{x} b$, where $\mathrm{a}$ and $\mathrm{b}$ represent the shorter and longer diameters of the tumor cell implanted proximal tibia, respectively (36).

qPCR analysis. Total RNA was extracted from cells and tumor tissues by selective binding to a silica-gel-based membrane using an RNeasy mini kit according to the manufacturer's 

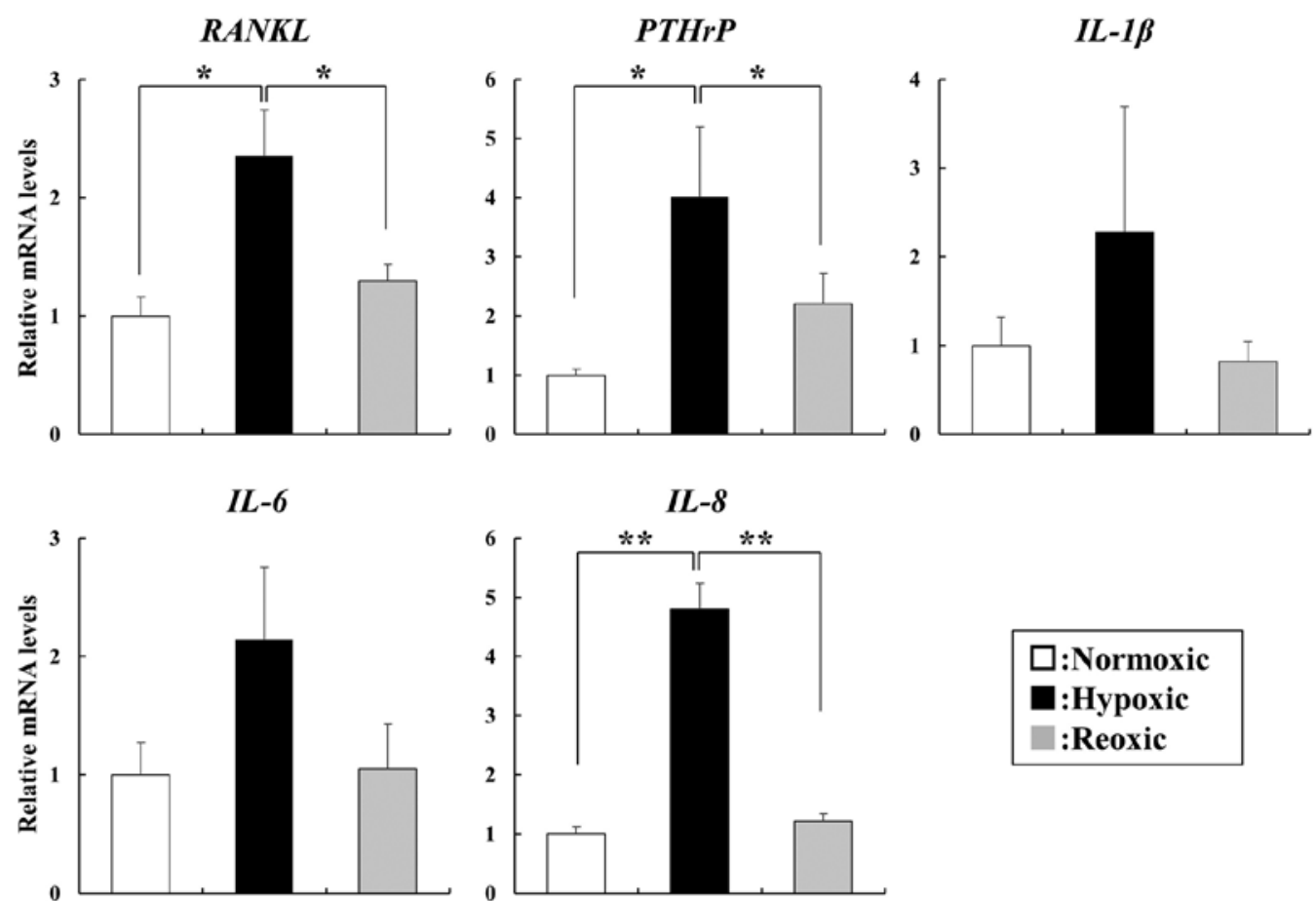

Figure 1. Effects of altered oxygen conditions on the expression of osteoclast-differentiation and osteolytic factors in MDA-MB-231 breast cancer cells in vitro. Cells were incubated for 6 days under one of three different oxygen conditions: normoxic $\left(20 \% \mathrm{O}_{2}, 5 \% \mathrm{CO}_{2}\right)$, hypoxic $\left(2 \% \mathrm{O}_{2}, 5 \% \mathrm{CO}_{2}\right)$ or reoxygenated conditions (incubated under normoxic conditions for 3 days followed by a 3-day incubation under hypoxic conditions). The mRNA expression of the osteoclastdifferentiation factor $(R A N K L)$ and osteolytic factors $(P T H r P, I L-1 \beta, I L-6$ and $I L-8)$ in cells was evaluated by qPCR. "P<0.05; ${ }^{* *} \mathrm{P}<0.01$.

protocol (Qiagen, Valencia, CA, USA). Oligo (dT)-primed first-stand cDNA was synthesized using a high-capacity cDNA transcription kit (Applied Biosystems, Foster City, CA, USA). qPCR was performed in a $20-\mu 1$ reaction mixture using SYBR Green Master Mix reagent (Applied Biosystems; Thermo Fisher Scientific, Inc., Foster City, CA, USA) on an ABI Prism 7500 sequence-detection system (Applied Biosystems; Thermo Fisher Scientific, Inc.). PCR conditions were as follows: one cycle at $95^{\circ} \mathrm{C}$ for $10 \mathrm{~min}$, followed by 40 cycles at $95^{\circ} \mathrm{C}$ for $15 \mathrm{sec}$ and $60^{\circ} \mathrm{C}$ for $1 \mathrm{~min}$. Pre-designed primers specific for $R A N K L, P T H r P, I L-1 \beta, I L-6$ and $I L-8$ were obtained from Invitrogen Life Technologies; Thermo Fisher Scientific, Inc. (Carlsbad, CA, USA). Primer sequences were as follows: RANKL forward, 5'-CCC AGA TCA AGG TGG TGT CT-3' and reverse, 5'-TGC TGA CCA ATG AGA GCA TC-3'; PTHrP forward, 5'-CAT CAG CTC CTC CAT GAC AA-3' and reverse, 5'-TCA GCT GTG TGG ATT TCT GC-3'; $I L-1 \beta$ forward, 5'-GGA CAA GCT GAG GAA GAT GC-3' and reverse, 5'-TCG TTA TCC CAT GTG TCG AA-3'; IL- 6 forward, 5'-AAA GAG GCA CTG GCA GAA AA-3' and reverse, 5'-TTT CAC CAG GCA AGT CTC CT-3'; IL-8 forward, 5'-GTT CCA CTG TGC CTT GGT TT-3' and reverse, 5'-GCT TCC ACA TGT CCT CAC AA-3'. Relative expression of $R A N K L, P T H r P, I L-1 \beta, I L-6$ and $I L-8$ was calculated using the $\Delta \Delta \mathrm{Cq}$ method (37), with normalization against $\beta$-actin levels.

Micro-computed tomography $(\mu C T)$ analysis. Quantitative analysis of treated tibiae was performed both before and after treatment using a $\mu \mathrm{CT}$ Scanner (R_mCT; Rigaku Mechatronics Co., Ltd., Tokyo, Japan). Following the end of treatment, all mice were euthanized by intraperitoneal injection of $1 \mathrm{ml}$ pentobarbital sodium (Kyoritsu Seiyaku, Tokyo, Japan), and the treated tibiae were removed. The bone samples were scanned by $\mu \mathrm{CT}$, and using the constructed sagittal image from the scanning data, histomorphometric analysis of the proximal epiphysis of the tibia, excluding the cortical bone, was performed. Bone volume was assessed using an imageanalysis system (TRI/3D-BON; Ratoc System Engineering, Tokyo, Japan). Following $\mu \mathrm{CT}$ scanning, samples were fixed in $10 \%$ formalin for $48 \mathrm{~h}$.

Hematoxylin and eosin $(H \& E)$ staining. Formalin-fixed tibia samples were decalcified in $10 \%$ ethylenediaminetetraacetic acid for 2 weeks and embedded in paraffin. Paraffin-embedded tibia samples were sliced into 6- $\mu \mathrm{m}$-thick sections and stained with H\&E. Sections were evaluated using a light microscope to confirm bone destruction and the presence of cancer cells.

Immunohistochemical analysis. Paraffin-embedded tibia sections were pretreated with citrate buffer for $40 \mathrm{~min}$ at $95^{\circ} \mathrm{C}$ and quenched with $0.05 \% \mathrm{H}_{2} \mathrm{O}_{2}$, followed by overnight incubation at $4^{\circ} \mathrm{C}$ with the following primary antibodies in Can Get Signal Immunostain Solution A (Toyobo, Osaka, Japan): mouse anti-HIF-1 $\alpha$ antibody (1:1,000; cat. no. sc-13515; Santa Cruz Biotechnology, Dallas, CA, USA), rabbit anti-RANKL antibody (1:1,000; cat. no. ab9957; Abcam, Tokyo, Japan), rabbit anti-IL-1 $\beta$ antibody (1:1,000; cat. no. ab9722; Abcam), mouse anti-IL-6 antibody (1:1,000; cat. no. sc-130326; Santa Cruz Biotechnology) and mouse anti-IL-8 antibody (1:1,000; cat. no. sc-7303; Santa Cruz Biotechnology). Following washes, the sections were incubated with horseradish 


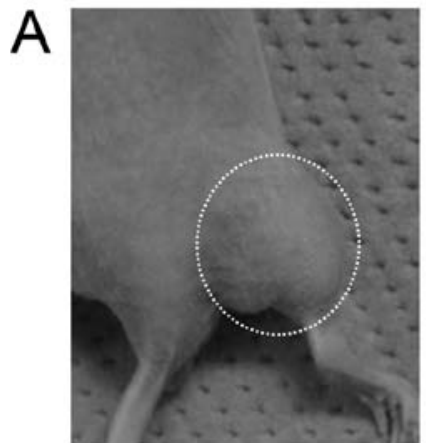

Control
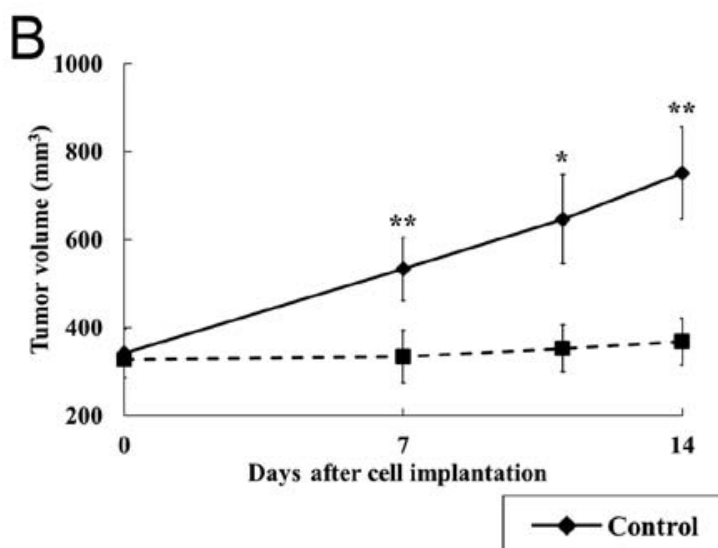

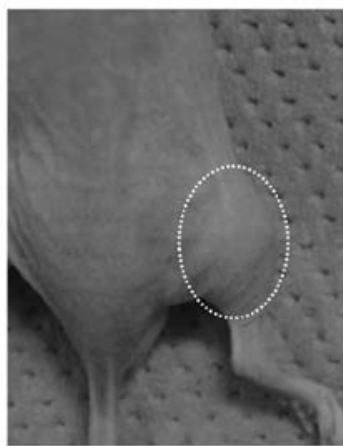

$\mathrm{CO}_{2}$

$\mathrm{C}_{40}$

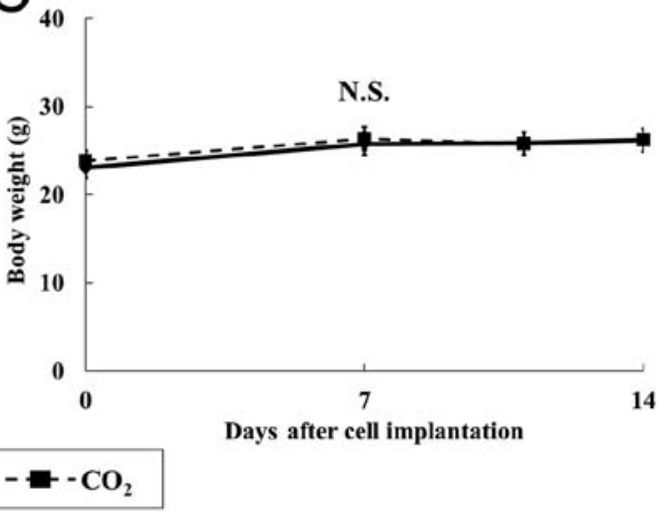

Figure 2. Effect of transcutaneous $\mathrm{CO}_{2}$ application in in vivo breast cancer growth. (A and $\mathrm{B}$ ) Tumor growth in both the $\mathrm{CO}_{2}$-treated and the control groups. ${ }^{*} \mathrm{P}<0.05 ;{ }^{* *} \mathrm{P}<0.01$. (C) Body weight in both the $\mathrm{CO}_{2}$-treated and the control groups.

peroxidase-conjugated labeled anti-mouse (cat. no. 424131) or anti-rabbit (cat. no. 424141) antibody (1:200; Histofine Simplestain Max PO; Nichirei, Tokyo, Japan) for an additional $30 \mathrm{~min}$ at room temperature, counterstained with hematoxylin, and examined with a BZ-X700 confocal microscope (Keyence Corporation, Osaka, Japan). Immunopositive cells were counted in three random fields under a high-power field (x200).

Tartrate-resistant acid phosphatase (TRAP) staining. To evaluate the effect of transcutaneous $\mathrm{CO}_{2}$ treatment on osteoclast activity in metastatic bone tumors, TRAP staining was performed in paraffin-embedded histological sections using the standard naphthol AS-BI phosphate post-coupling method (38). Slides were incubated at $37^{\circ} \mathrm{C}$ in sodium acetate buffer ( $\mathrm{pH}$ 5.0) containing $0.01 \%$ naphthol AS-BI phosphate and $0.5 \mathrm{Ml}-(+)$ tartaric acid. The sections were then incubated in the same buffer containing pararosaniline chloride for $20 \mathrm{~min}$, followed by washing in distilled water. The sections were counterstained with hematoxylin for $30 \mathrm{sec}$, dehydrated with alcohol and penetrated with xylene. TRAP-positive multinucleated cells containing more than three nuclei were counted as osteoclasts in three random fields under a light microscopy.

Statistical analysis. All experiments were performed independently in triplicate, and data are presented as the mean \pm standard error of the mean (SEM) unless otherwise indicated. Differences between groups were evaluated using the Mann-Whitney U test and also by analysis of variance (ANOVA) with a Tukey's post hoc test to compare continuous values. All tests were considered to indicate a statistically significant difference at $\mathrm{P}<0.05$.

\section{Results}

Hypoxic conditions increase mRNA expression of osteoclastdifferentiation and osteolytic factors in MDA-MB-231 breast cancer cells in vitro. The mRNA expression of RANKL, PTHrP and IL-8 was significantly increased in cells under hypoxic conditions compared with their expression observed under normoxic conditions $(\mathrm{P}<0.05)$, with the elevated expression of the three factors subsequently decreased to the same levels as those under normoxic conditions following reoxygenation (Fig. 1). We also observed elevated expression of IL-1 $\beta$ and IL-6 under hypoxic conditions, however, this increase was not statistically significant (Fig. 1).

Transcutaneous $\mathrm{CO}_{2}$ application suppresses tumor growth and prevents bone destruction in a bone metastatic model of human breast cancer. Transcutaneous $\mathrm{CO}_{2}$ treatment significantly suppressed breast cancer tumor growth compared with that observed in controls (Fig. 2A). In addition, at the end of the experiment, the tumor volume in the $\mathrm{CO}_{2}$ group was $49 \%$ of that in the control group (Fig. 2B) $(\mathrm{P}<0.05)$. There was no significant difference in body weight between the groups (Fig. 2C).

$\mu \mathrm{CT}$ analyses demonstrated that transcutaneous $\mathrm{CO}_{2}$ application blocked bone destruction compared with the control treatment, and that bone volume was significantly preserved in the $\mathrm{CO}_{2}$ group (Fig. 3A and B). H\&E staining of treated tibiae 
A
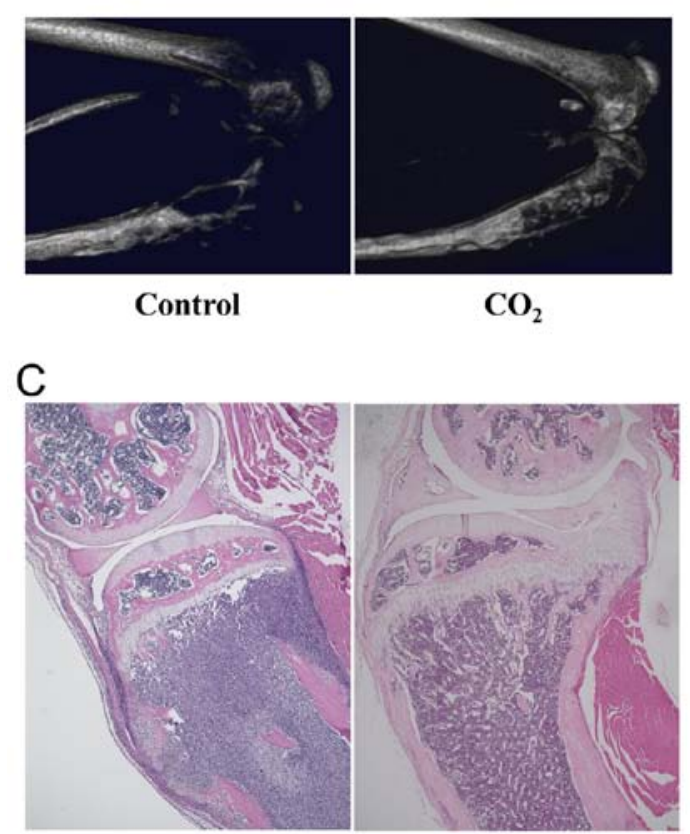

Control

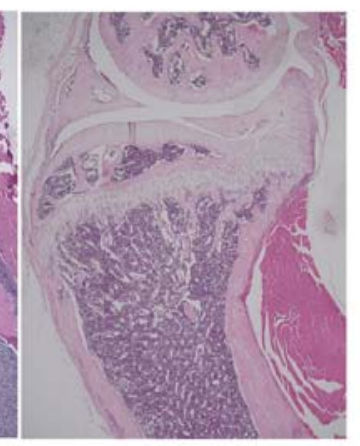

$\mathrm{CO}_{2}$
B

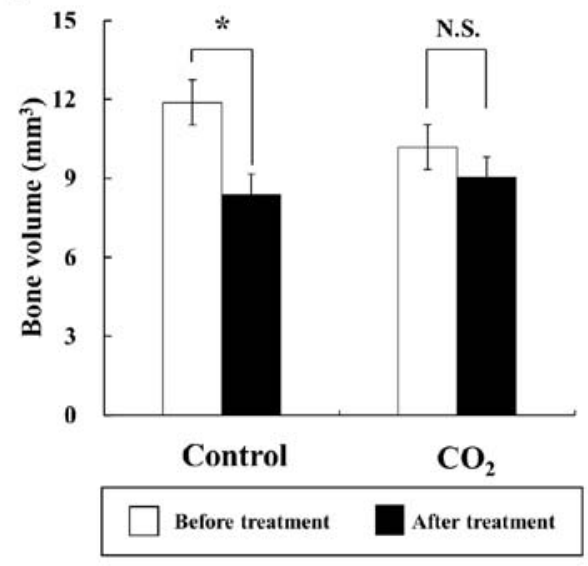

Figure 3. Effect of transcutaneous $\mathrm{CO}_{2}$ application on bone destruction in treated tibiae following breast cancer-cell implantation. (A) Three-dimensional

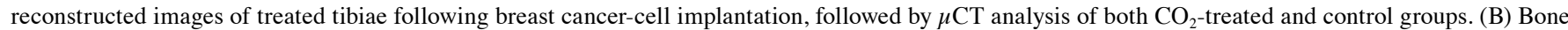
volume before and after treatment was analyzed in both the $\mathrm{CO}_{2}$-treated and the control groups. ${ }^{*} \mathrm{P}<0.05$. (C) $\mathrm{H} \& \mathrm{E}$ staining of the treated tibiae in both the $\mathrm{CO}_{2}$-treated and the control groups.

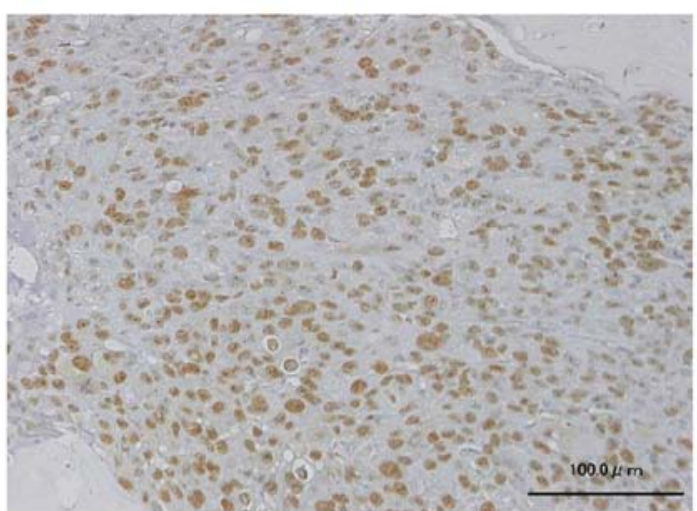

Control

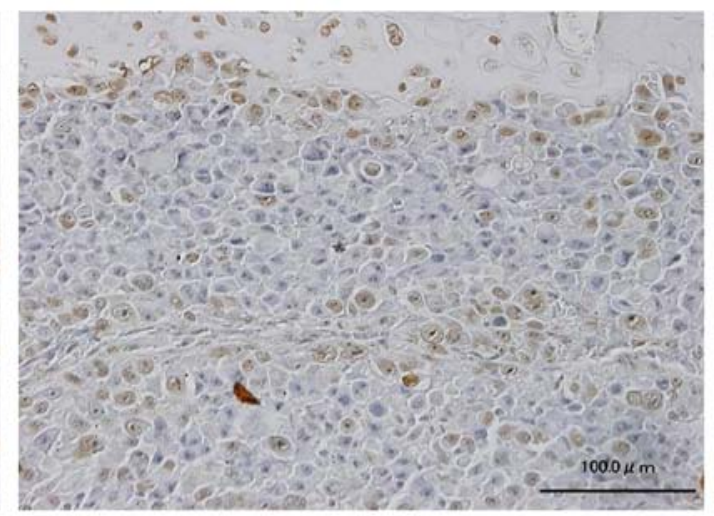

$\mathrm{CO}_{2}$

Figure 4. Immunohistochemical staining for HIF-1 $\alpha$ in tibiae from both the $\mathrm{CO}_{2}$-treated and the control groups.

also revealed that the area of cancer tissues in the $\mathrm{CO}_{2}$ group was smaller than that in the control group (Fig. 3C).

Osteoclast activity is significantly inhibited by transcutaneous $\mathrm{CO}_{2}$ application and via decreased expression of osteoclast-differentiation and osteolytic factors along with decreased HIF-1 $\alpha$ expression. Immunopositive staining for $\mathrm{HIF}-1 \alpha$ was weakly detected in $\mathrm{CO}_{2}$-treated tibiae, whereas positive staining was extensively observed in the control tibiae (Fig. 4). For TRAP staining, the number of TRAPpositive multinucleated osteoclasts was significantly reduced following transcutaneous $\mathrm{CO}_{2}$ treatment compared with that observed in the controls (Fig. 5A and B). Additionally, immunohistochemical staining for osteoclast-differentiation and osteolytic factors revealed that staining for RANKL, IL-1 $\beta$, IL-6 and IL-8 was barely detectable in the $\mathrm{CO}_{2}$-treated tibiae, but was strongly positive in the control group (Fig. 6A). Furthermore, the number of cells immunopositive for these factors in the $\mathrm{CO}_{2}$-treated tumors was significantly decreased compared with that observed in the control tumors (Fig. 6B).

\section{Discussion}

In the area of bone metastasis, osteolysis is mainly caused by activated osteoclast function and not by the direct effects of metastatic cancer cells $(4,39)$. In response to factors 

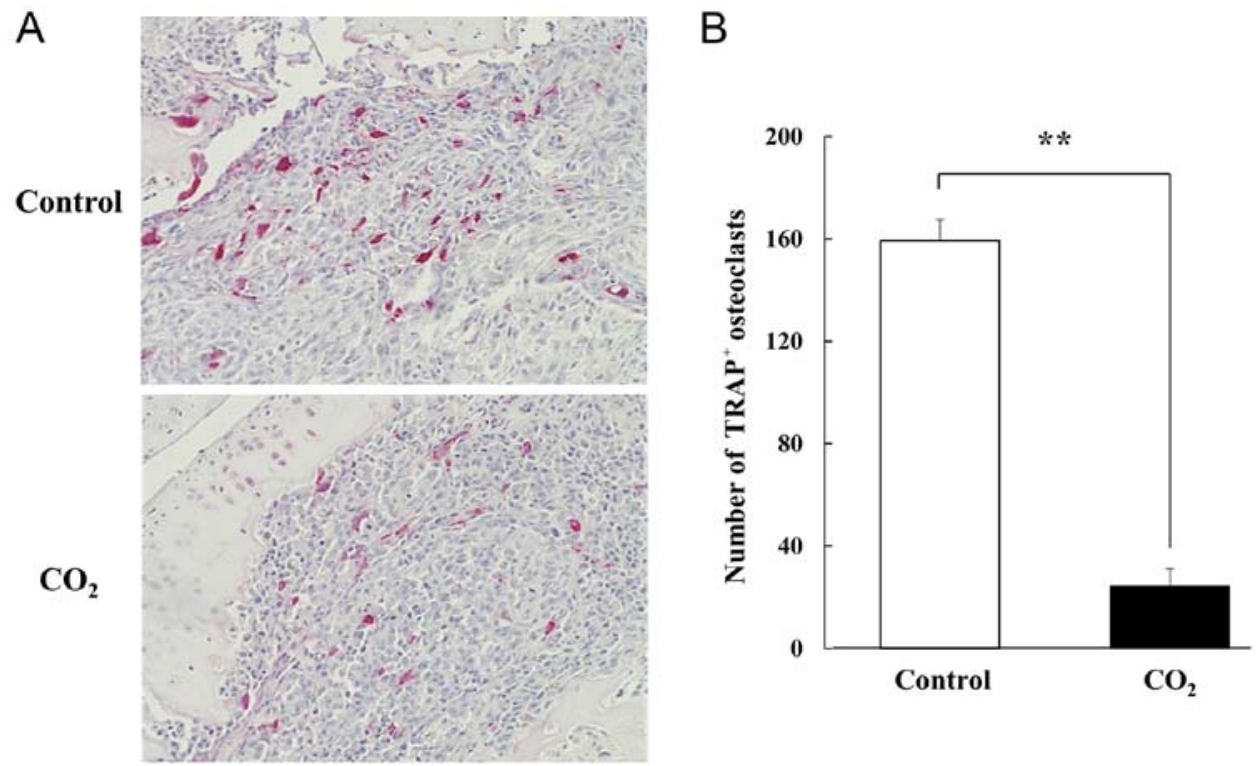

Figure 5. Osteoclast activity following transcutaneous $\mathrm{CO}_{2}$ application. (A) TRAP staining of treated tibiae from both the $\mathrm{CO}_{2}$-treated and the control groups (B) Assessment of the number of TRAP-positive multinucleated cells counted as osteoclasts. ${ }^{* *} \mathrm{P}<0.01$.

A

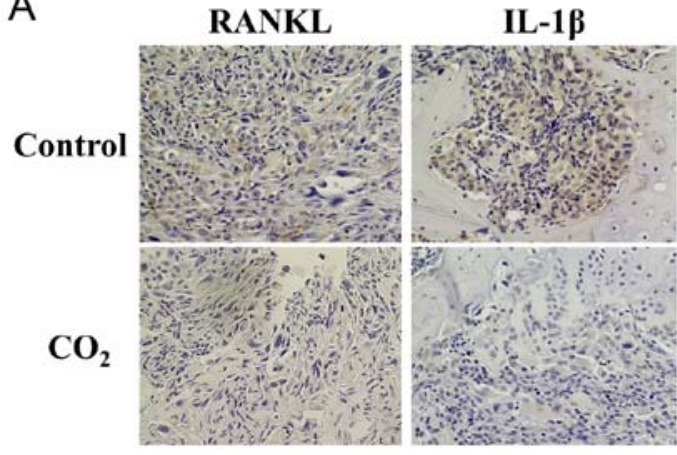

IL-6

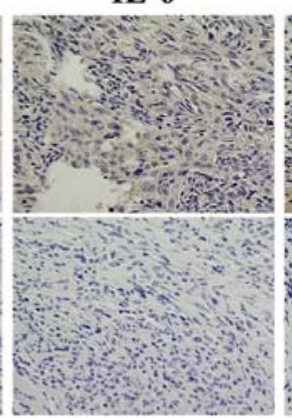

IL-8

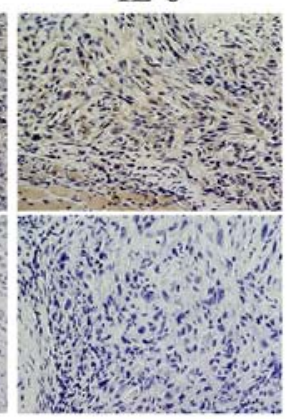

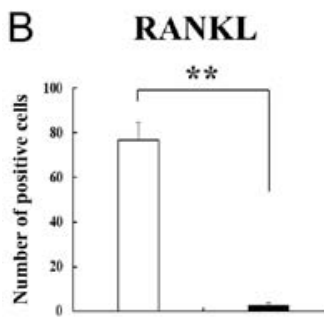
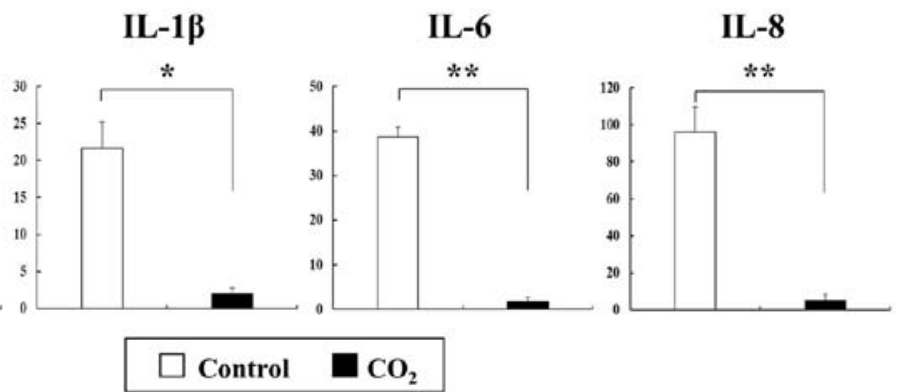

Figure 6. Effects of transcutaneous $\mathrm{CO}_{2}$ application on the expression of osteoclast-differentiation and osteolytic factors in breast cancer cells in vivo. (A) Immunohistochemical staining for RANKL, IL-1 1 , IL-6 and IL-8 in both the $\mathrm{CO}_{2}$-treated and the control groups. (B) The number of immunopositive cells was evaluated. ${ }^{*} \mathrm{P}<0.05 ;{ }^{* *} \mathrm{P}<0.01$.

associated with osteoclast differentiation (RANKL) and osteolysis (PTHrP, IL-1 $\beta$, IL-6 and IL-8), which are produced by cancer cells, osteoblast-mediated cross-talk between RANKL and its receptor, RANK, which is expressed in hematopoietic osteoclast-precursor cells and mature osteoclasts, is promoted, followed by stimulation of osteoclast activity, especially boneresorptive functions (5-7,40-42). In particular, PTHrP induced osteoclast formation through the upregulation of RANKL (42) and represented a specific mediator of osteolysis in metastatic breast cancer $(43,44)$. Previous studies reported that breast cancer cells secreted high levels of RANKL, IL-1 $\beta$ and IL-6 under hypoxic conditions (45-47). In the present study using MDA-MB-231 breast cancer cells, we observed that the in vitro expression of factors, including RANKL, PTHrP, IL-1 $\beta$, IL-6 and IL-8, was increased under hypoxic conditions and subsequently decreased by reoxygenation. These findings were consistent with previous studies (45-47) and indicated that hypoxic conditions affected the expression of osteoclastdifferentiation and osteolytic factors, which play essential roles in bone destruction associated with cancer metastasis. 
Based on these findings, we hypothesized that improving hypoxia could suppress the stimulation of osteoclast activity, and that recovery from hypoxia would inhibit bone destruction by cancer metastasis.

Hypoxia is a common feature of solid tumors, including metastatic bone tumors, and is mainly a consequence of poor perfusion in solid tumors. In bone metastasis, abnormal blood vessels are insufficient to supply oxygen to metastatic tumor tissues, causing intratumoral hypoxia (48). The median tumor oxygen concentration in breast cancer is reportedly $\leq 1.3 \%$, which is substantially lower than that in normal tissues (25). Hypoxia negatively affects clinical outcomes, including overall patient survival, motility, and resistance to chemotherapy and/or radiotherapy by impacting tumor-cell functions. The transcription factor HIF-1 is a key regulator of the cellular response promoting survival in the hostile environment of hypoxic tumors (23). In human malignancies, HIFs critically contribute to chemoresistance and/or radioresistance (49) and are associated with histological grade, stage and local or distant recurrence (50-53). Recently, a role for HIF-1 $\alpha$ in promoting lung and bone metastases was described using a transgenic model of breast cancers (25). Therefore, improvement of hypoxic conditions by regulating HIF- $1 \alpha$ in metastatic bone tumors may control not only tumor progression, but also bone destruction. Although several therapeutic strategies to overcome hypoxia and/or to specifically target hypoxic cells have been investigated, attempts to improve tumor oxygen levels have not yielded clinically compelling results (54-56), and metastatic bone tumors are still considered an incurable disease. Recent therapeutic strategies for treating bone metastasis include surgery, radiotherapy and osteoclast inhibitors, such as bisphosphonates and denosumab, the human monoclonal antibody used to neutralize RANKL. Regardless of the wide use of these treatments, radiotherapy should still be administered for symptom palliation (57), although bisphosphonates and denosumab can cause unfavorable side-effects, such as osteonecrosis of the jaw (11-14). Based on these findings, new strategies for the treatment of bone metastases with fewer side-effects are required.

The benefits of $\mathrm{CO}_{2}$ therapy have been realized for therapeutic purposes, especially in the treatment of peripheral vascular disorders (58), and carbonated spa therapy has historically been used in Europe as an effective treatment for cardiac diseases and skin problems $(59,60)$. The therapeutic effects of $\mathrm{CO}_{2}$ are mediated by an increase in blood flow and microcirculation, nitric oxide-dependent neocapillary formation and an increase in the partial pressure of $\mathrm{O}_{2}$ in local tissue, known as the Bohr effect (27). The Bohr effect is represented by a rightward shift in the $\mathrm{O}_{2}$-hemoglobin dissociation curve accompanied with increased $\mathrm{pCO}_{2}$ or decreased $\mathrm{pH}$ (27). We previously demonstrated that transcutaneous $\mathrm{CO}_{2}$ application increased $\mathrm{O}_{2}$ pressure in treated tissues, through the absorption of $\mathrm{CO}_{2}$, potentially causing an artificial Bohr effect (28). Transcutaneous $\mathrm{CO}_{2}$ application suppressed the in vivo human undifferentiated pleomorphic sarcoma/malignant fibrous histiocytoma tumor growth through induction of mitochondrial apoptosis accompanied by mitochondrial proliferation (29). Additionally, animal models of osteosarcoma (30) and oral squamous cell carcinoma (31) demonstrated that $\mathrm{CO}_{2}$ treatment decreased metastatic potential along with decreased expression of both HIF-1 $\alpha$ and vascular endothelial growth factor $(30,31)$. These findings strongly indicated that transcutaneous $\mathrm{CO}_{2}$ application exhibited antitumor effects by improving hypoxic conditions within tumor tissues (29-31). In the present study, we revealed that transcutaneous $\mathrm{CO}_{2}$ application in a bone metastatic model of human breast cancer, significantly improved intratumoral hypoxia along with decreased expression of HIF-1 $\alpha$, RANKL and osteolytic factors, as well as suppressed osteoclast function along with decreased TRAP activity, resulting in blockage of progressive bone destruction without observable side-effects.

However, the present study had several limitations. Firstly, we have not examined the influence of $\mathrm{CO}_{2}$ application on osteoblasts in the surrounding tissues. We previously reported that $\mathrm{CO}_{2}$ application accelerated fracture repair in a rat-fracture model by increasing osteoblast activity (61). In addition, several studies revealed that, in the presence of osteolytic bone metastasis, tumor cells increased the RANKL production of osteoblasts in the surrounding bone stroma of the host with decreased osteoprotegerin, by releasing a variety of factors including interleukins and PTHrP, resulting in more osteoclast formation and bone degradation $(62,63)$. Based on these previous studies, $\mathrm{CO}_{2}$ application may inhibit the tumor-induced RANKL production of osteoblasts, resulting in decreased bone destruction via decreased osteoclast activity. Secondly, we observed that transcutaneous $\mathrm{CO}_{2}$ application could inhibit metastatic bone destruction along with decreased osteoclast activity in a well-established bone metastatic model using MDA-MB-231 human breast cancer cells, however we used only one breast cancer cell line in the present study. Additionally, we did not directly assess the oxygen conditions in the metastatic bone during transcutaneous $\mathrm{CO}_{2}$ treatment. Therefore, further investigations are required to clarify the effects of transcutaneous $\mathrm{CO}_{2}$ application on cancer cells and bone destruction in metastatic bone tumors. In conclusion, our findings strongly indicated that oxygen conditions affected the expression of osteoclast-differentiation and osteolytic factors, which play essential roles in bone destruction by breast cancer cells, and that transcutaneous $\mathrm{CO}_{2}$ application blocked metastatic bone destruction by improving hypoxic conditions along with decreased expression of osteolytic factors and TRAP activity. Although further studies are required to elucidate the mechanisms associated with the effects of $\mathrm{CO}_{2}$ application, transcutaneous $\mathrm{CO}_{2}$ application can be considered a potential therapeutic strategy for the treatment of metastatic bone destruction in breast cancer patients.

\section{Acknowledgements}

We thank Mrs. Minako Nagata, Mrs. Maya Yasuda and Mrs. Kyoko Tanaka for their expert technical assistance. The abstract was presented at the 2018 Annual Meeting of the Orthopaedic Research Society Mar. 10-13, 2018 in New Orleans, LA, USA and was published as abstract no. 2073.

\section{Funding}

No funding was received. 


\section{Availability of data and materials}

The datasets used and analyzed during the current study are available from the corresponding author upon reasonable request.

\section{Authors' contributions}

TT, TK, TU, MT, NF, HH, TN, RK and TA conceived and designed the study. TT performed the experiments and wrote the initial draft of the manuscript. TT, TU, MT, MM, SF and EK performed the analyses and interpretation of data. TK is the principal investigator and was involved in the conceptualization, experimental design, discussion of the data, and writing of the manuscript. All authors read and approved the manuscript and agree to be accountable for all aspects of the research in ensuring that the accuracy or integrity of any part of the work are appropriately investigated and resolved.

\section{Ethics approval and consent to participate}

All animal experiments were approved by the Ethics Committee of Kobe University Animal Experimentation Regulations (permission no: P120404-R1).

\section{Patient consent for publication}

Not applicable.

\section{Competing interests}

The hydro-gel was donated from Neochemir, Inc. TU is a fulltime employee of Neochemir, Inc. The international patent publication number is WO2004/002393, with a publication date of January 8,2004 . This does not alter the author's adherence to all journal policies on sharing data and materials.

\section{References}

1. Jemal A, Bray F, Center MM, Ferlay J, Ward E and Forman D: Global cancer statistics. CA Cancer J Clin 61: 69-90, 2011.

2. Coleman RE: Clinical features of metastatic bone disease and risk of skeletal morbidity. Clin Cancer Res 12: 6243s-6249s, 2006.

3. Steinauer K, Huang DJ, Eppenberger-Castori S, Amann E and Güth U: Bone metastases in breast cancer: Frequency, metastatic pattern and non-systemic locoregional therapy. J Bone Oncol 3: 54-60, 2014.

4. Thomas RJ, Guise TA, Yin JJ, Elliott J, Horwood NJ, Martin TJ and Gillespie MT: Breast cancer cells interact with osteoblasts to support osteoclast formation. Endocrinology 140: 4451-4458, 1999.

5. Kearns AE, Khosla S and Kostenuik PJ: Receptor activator of nuclear factor kappaB ligand and osteoprotegerin regulation of bone remodeling in health and disease. Endocr Rev 29: 155-192, 2008.

6. Blair JM, Zhou H, Seibel MJ and Dunstan CR: Mechanisms of disease: Roles of OPG, RANKL and RANK in the pathophysiology of skeletal metastasis. Nat Clin Pract Oncol 3: 41-49, 2006.

7. Suda T, Takahashi N, Udagawa N, Jimi E, Gillespie MT and Martin TJ: Modulation of osteoclast differentiation and function by the new members of the tumor necrosis factor receptor and ligand families. Endocr Rev 20: 345-357, 1999.

8. Gonzalez-Suarez E, Jacob AP, Jones J, Miller R, Roudier-Meyer MP, Erwert R, Pinkas J, Branstetter D and Dougall WC: RANK ligand mediates progestin-induced mammary epithelial proliferation and carcinogenesis. Nature 468: 103-107, 2010.
9. Canon JR, Roudier M, Bryant R, Morony S, Stolina M, Kostenuik PJ and Dougall WC: Inhibition of RANKL blocks skeletal tumor progression and improves survival in a mouse model of breast cancer bone metastasis. Clin Exp Metastasis 25: $119-129,2008$

10. Roodman GD and Dougall WC: RANK ligand as a therapeutic target for bone metastases and multiple myeloma. Cancer Treat Rev 34: 92-101, 2008.

11. Von Hoff DD, Layard MW, Basa P, Davis HL Jr, Von Hoff AL, Rozencweig $M$ and Muggia FM: Risk factors for doxorubicininduced congestive heart failure. Ann Intern Med 91: 710-717, 1979.

12. Luu T, Chung $\mathrm{C}$ and Somlo G: Combining emerging agents in advanced breast cancer. Oncologist 16: 760-771, 2011.

13. Vyas S, Hameed S and Murugaraj V: Denosumab-associated osteonecrosis of the jaw - a case report. Dent Update 41: 449-450, 2014.

14. O'Halloran M, Boyd NM and Smith A: Denosumab and osteonecrosis of the jaws - the pharmacology, pathogenesis and a report of two cases. Aust Dent J 59: 516-519, 2014.

15. Vaupel P and Harrison L: Tumor hypoxia: Causative factors, compensatory mechanisms, and cellular response. Oncologist 9 (Suppl 5): 4-9, 2004.

16. Höckel M and Vaupel P: Tumor hypoxia: Definitions and current clinical, biologic, and molecular aspects. J Natl Cancer Inst 93: 266-276, 2001.

17. Harris AL: Hypoxia - a key regulatory factor in tumour growth. Nat Rev Cancer 2: 38-47, 2002.

18. Zhong H, De Marzo AM, Laughner E, Lim M, Hilton DA, Zagzag D, Buechler P, Isaacs WB, Semenza GL and Simons JW: Overexpression of hypoxia-inducible factor 1alpha in common human cancers and their metastases. Cancer Res 59: 5830-5835, 1999.

19. Rundqvist $H$ and Johnson RS: Tumour oxygenation: Implications for breast cancer prognosis. J Intern Med 274: 105-112, 2013.

20. Siclari VA, Mohammad KS, Tompkins DR, Davis H, McKenna CR, Peng X, Wessner LL, Niewolna M, Guise TA, Suvannasankha A, et al: Tumor-expressed adrenomedullin accelerates breast cancer bone metastasis. Breast Cancer Res 16: 458,2014

21. de Castro Junior G, Puglisi F, de Azambuja E, El Saghir NS and Awada A: Angiogenesis and cancer: A cross-talk between basic science and clinical trials (the 'do ut des' paradigm). Crit Rev Oncol Hematol 59: 40-50, 2006.

22. Pugh CW and Ratcliffe PJ: Regulation of angiogenesis by hypoxia: Role of the HIF system. Nat Med 9: 677-684, 2003.

23. Tang ZN, Zhang F, Tang P, Qi XW and Jiang J: Hypoxia induces RANK and RANKL expression by activating HIF-1 $\alpha$ in breast cancer cells. Biochem Biophys Res Commun 408: 411-416, 2011.

24. Kallergi G, Markomanolaki H, Giannoukaraki V, Papadaki MA, Strati A, Lianidou ES, Georgoulias V, Mavroudis D and Agelaki S: Hypoxia-inducible factor-1alpha and vascular endothelial growth factor expression in circulating tumor cells of breast cancer patients. Breast Cancer Res 11: R84, 2009.

25. Hiraga T, Kizaka-Kondoh S, Hirota K, Hiraoka M and Yoneda T: Hypoxia and hypoxia-inducible factor-1 expression enhance osteolytic bone metastases of breast cancer. Cancer Res 67: 41574163, 2007.

26. Hansen TN, Sonoda Y and McIlroy MB: Transfer of oxygen, nitrogen, and carbon dioxide through normal adult human skin. J Appl Physiol 49: 438-443, 1980.

27. Bohr C, Hasselbach K and Krogh A: Ueber emen in biologischen Bezuehung wichtigen Einfluss, den die Kohlen saurespannung des Blutes anf dessen Samerstoffbinding ubt. Arch Physiol 16: 402-412, 1904

28. Sakai Y, Miwa M, Oe K, Ueha T, Koh A, Niikura T, Iwakura T, Lee SY, Tanaka M and Kurosaka M: A novel system for transcutaneous application of carbon dioxide causing an 'artificial Bohr effect' in the human body. PLoS One 6: e24137, 2011.

29. Onishi Y, Kawamoto T, Ueha T, Kishimoto K, Hara H, Fukase N, Toda M, Harada R, Minoda M, Sakai Y, et al: Transcutaneous application of carbon dioxide $\left(\mathrm{CO}_{2}\right)$ induces mitochondrial apoptosis in human malignant fibrous histiocytoma in vivo. PLoS One 7: e49189, 2012.

30. Harada R, Kawamoto T, Ueha T, Minoda M, Toda M, Onishi Y, Fukase N, Hara H, Sakai Y, Miwa M, et al: Reoxygenation using a novel $\mathrm{CO}_{2}$ therapy decreases the metastatic potential of osteosarcoma cells. Exp Cell Res 319: 1988-1997, 2013. 
31. Takeda D, Hasegawa T, Ueha T, Imai Y, Sakakibara A, Minoda M, Kawamoto T, Minamikawa T, Shibuya Y, Akisue T, et al: Transcutaneous carbon dioxide induces mitochondrial apoptosis and suppresses metastasis of oral squamous cell carcinoma in vivo. PLoS One 9: e100530, 2014.

32. Onishi Y, Kawamoto T, Ueha T, Hara H, Fukase N, Toda M, Harada R, Sakai Y, Miwa M, Nishida K, et al: Transcutaneous application of Carbon Dioxide $\left(\mathrm{CO}_{2}\right)$ enhances chemosensitivity by reducing hypoxic conditions in human malignant fibrous histiocytoma. J Cancer Sci Ther 4: 174-181, 2012.

33. Bobrova TS, Kriukova IN, Voronina AN and Bassalyk LS: Study of the 'continuous cell antigen' and the human gastric mucosa Biull Eksp Biol Med 86: 744-747, 1978 (In Russian)

34. Okada Y, Ueno H, Katagiri M, Oneyama T, Shimomura K, Sakurai S, Mataga I, Moride M and Hasegawa H: Experimental study of antiangiogenic gene therapy targeting VEGF in oral cancer. Odontology 98: 52-59, 2010.

35. Oe K, Ueha T, Sakai Y, Niikura T, Lee SY, Koh A, Hasegawa T, Tanaka M, Miwa M and Kurosaka M: The effect of transcutaneous application of carbon dioxide $\left(\mathrm{CO}_{2}\right)$ on skeletal muscle. Biochem Biophys Res Commun 407: 148-152, 2011.

36. Okada Y, Akisue T, Hara H, Kishimoto K, Kawamoto T, Imabori M, Kishimoto S, Fukase N, Onishi Y and Kurosaka M: The effect of bevacizumab on tumour growth of malignant fibrous histiocytoma in an animal model. Anticancer Res 30 : 3391-3395, 2010.

37. Livak KJ and Schmittgen TD: Analysis of relative gene expression data using real-time quantitative PCR and the 2(- $\Delta \Delta C(\mathrm{~T}))$ Method. Methods 25: 402-408, 2001.

38. Modderman WE, Tuinenburg-Bol Raap AC and Nijweide PJ: Tartrate-resistant acid phosphatase is not an exclusive marker for mouse osteoclasts in cell culture. Bone 12: 81-87, 1991.

39. Boyde A, Maconnachie E, Reid SA, Delling G and Mundy GR: Scanning electron microscopy in bone pathology: Review of methods, potential and applications. Scan Electron Microsc 4: $1537-1554,1986$

40. Kozlow W and Guise TA: Breast cancer metastasis to bone: Mechanisms of osteolysis and implications for therapy. J Mammary Gland Biol Neoplasia 10: 169-180, 2005.

41. Bendre MS, Montague DC, Peery T, Akel NS, Gaddy D and Suva LJ: Interleukin-8 stimulation of osteoclastogenesis and bone resorption is a mechanism for the increased osteolysis of metastatic bone disease. Bone 33: 28-37, 2003.

42. Roodman GD: Biology of osteoclast activation in cancer. J Clin Oncol 19: 3562-3571, 2001.

43. Bryden AA, Hoyland JA, Freemont AJ, Clarke NW and George NJ: Parathyroid hormone related peptide and receptor expression in paired primary prostate cancer and bone metastases. Br J Cancer 86: 322-325, 2002

44. Miki T, Yano S, Hanibuchi M and Sone S: Bone metastasis model with multiorgan dissemination of human small-cell lung cancer (SBC-5) cells in natural killer cell-depleted SCID mice. Oncol Res 12: 209-217, 2000.

45. Rattigan Y, Hsu JM, Mishra PJ, Glod J and Banerjee D: Interleukin 6 mediated recruitment of mesenchymal stem cells to the hypoxic tumor milieu. Exp Cell Res 316: 3417-3424, 2010

46. Filippi I, Carraro F and Naldini A: Interleukin-1 $\beta$ affects MDAMB231 breast cancer cell migration under hypoxia: Role of HIF-1 $\alpha$ and NFKB transcription factors. Mediators Inflamm 2015: 789414,2015
47. Tang ZN, Zhang F, Tang P, Qi XW and Jiang J: Hypoxia induces RANK and RANKL expression by activating HIF-1 $\alpha$ in breast cancer cells Biochem Biophys Res Commun 408: 411-416, 2011.

48. Jain RK: Normalization of tumor vasculature: An emerging concept in antiangiogenic therapy. Science 307: 58-62, 2005.

49. Vaupel P and Mayer A: Hypoxia in cancer: Significance and impact on clinical outcome. Cancer Metastasis Rev 26: 225-239, 2007.

50. Miyazawa M, Yasuda M, Fujita M, Hirasawa T, Kajiwara H, Hirabayashi K, Ogane N, Shimizu M, Asanuma H, Murakami M, et al: Association of hypoxia-inducible factor-1 expression with histology in epithelial ovarian tumors: A quantitative analysis of HIF-1. Arch Gynecol Obstet 279: 789-796, 2009.

51. Zeng W, Wan R, Zheng Y, Singh SR and Wei Y: Hypoxia, stem cells and bone tumor. Cancer Lett 313: 129-136, 2011.

52. Rohwer $\mathrm{N}$ and Cramer T: Hypoxia-mediated drug resistance: Novel insights on the functional interaction of HIFs and cell death pathways. Drug Resist Updat 14: 191-201, 2011.

53. Schwab LP, Peacock DL, Majumdar D, Ingels JF, Jensen LC, Smith KD, Cushing RC and Seagroves TN: Hypoxia-inducible factor $1 \alpha$ promotes primary tumor growth and tumor-initiating cell activity in breast cancer. Breast Cancer Res 14: R6, 2012.

54. Teicher BA: Combination of perfluorochemical emulsions and carbogen breathing with cancer chemotherapy. Artif Cells Blood Substit Immobil Biotechnol 22: 1109-1120, 1994.

55. Kawasoe Y, Yokouchi M, Ueno Y, Iwaya H, Yoshida H and Komiya S: Hyperbaric oxygen as a chemotherapy adjuvant in the treatment of osteosarcoma. Oncol Rep 22: 1045-1050, 2009.

56. Kaanders JH, Bussink J and van der Kogel AJ: Clinical studies of hypoxia modification in radiotherapy. Semin Radiat Oncol 14 233-240, 2004

57. Budach W: Radiotherapy in patients with metastatic breast cancer. Eur J Cancer 47 (Suppl 3): S23-S27, 2011.

58. Blair DA, Glover WE and McArrdle L: The mechanism of the peripheral vasodilation following carbon dioxide inhalation in man. Clin Sci 19: 407-423, 1960.

59. Matz H, Orion E and Wolf R: Balneotherapy in dermatology. Dermatol Ther 16: 132-140, 2003.

60. Hartmann BR, Bassenge E, Pittler M and Hartmann BR Effect of carbon dioxide-enriched water and fresh water on the cutaneous microcirculation and oxygen tension in the skin of the foot. Angiology 48: 337-343, 1997.

61. Koga T, Niikura T, Lee SY, Okumachi E, Ueha T, Iwakura T, Sakai Y, Miwa M, Kuroda R and Kurosaka M: Topical cutaneous $\mathrm{CO}_{2}$ application by means of a novel hydrogel accelerates fracture repair in rats. J Bone Joint Surg Am 96: 2077-2084, 2014.

62. Trinkaus M, Ooi WS, Amir E, Popovic S, Kalina M, Kahn H, Singh G, Gainford MC and Clemons M: Examination of the mechanisms of osteolysis in patients with metastatic breast cancer. Oncol Rep 21: 1153-1159, 2009.

63. Chen YC, Sosnoski DM and Mastro AM: Breast cancer metastasis to the bone: Mechanisms of bone loss. Breast Cancer Res 12: 215, 2010. 